\title{
Mitochondrial superoxide dismutase is essential for ethanol tolerance of Saccharomyces cerevisiae in the post-diauxic phase
}

\author{
V. Costa, M. A. Amorim, E. Reis, $†$ A. Quintanilha and P. Moradas-Ferreira \\ Author for correspondence: P. Moradas-Ferreira. Tel: +351 2 310359. Fax: + 35122001918 \\ e-mail: pmferrei@ncc.up.pt
}

Instituto de Ciências Biomédicas de Abel Salazar, Departamento de Biologia Molecular, e Centro de Citologia Experimental, Universidade do Porto, Portugal

\begin{abstract}
This work reports the role of both superoxide dismutases - CuZnSOD (encoded by SOD1) and MnSOD (encoded by SOD2) - in the build-up of tolerance to ethanol during growth of Saccharomyces cerevisiae from exponential to postdiauxic phase. Both enzyme activities increase from the exponential phase to the diauxic shift and from the diauxic shift to the post-diauxic phase. The levels of MRNA-SOD1 and MRNA-SOD2 increase from the exponential phase to the diauxic shift; however, during the post-diauxic phase mRNA-SOD1 levels decrease while mRNA-SOD2 levels remain unchanged. These data indicate the existence of two regulatory mechanisms involved in the induction of SOD activity during growth: synthesis de novo of the proteins (until the diauxic shift), and post-transcriptional or post-translational regulation (during the post-diauxic phase). Ethanol does not alter the activities of either enzyme in cells from the diauxic shift or post-diauxic phases, although the respective mRNA levels decrease in post-diauxic-phase cells treated with ethanol ( $14 \%$ or $20 \%$ ). Results of experiments with sod1 and sod 2 mutants show that MnSOD, but not CuZnSOD, is essential for ethanol tolerance of diauxic-shift and postdiauxic-phase cells. Evidence that ethanol toxicity is correlated with the production of reactive oxygen species in the mitochondria is obtained from results with respiration-deficient mutants. In these cells, the induction of superoxide dismutase activity by ethanol is low; also, the respiratory deficiency restores the capacity of sod 2 cells to acquire ethanol tolerance.
\end{abstract}

Keywords: yeast, ethanol tolerance, superoxide dismutase, post-diauxic phase

\section{INTRODUCTION}

The increasing ethanol concentration during batch fermentation affects the growth, viability and fermentation rate of Saccharomyces cerevisiae cells (van Uden, 1984); this toxicity has been associated with protein denaturation and membrane fluidity, leading to membrane leakage (Casey \& Ingledew, 1986; Piper, 1995). Ethanol has also been considered to be responsible for promoting mitochondrial DNA mutagenesis (Bandas \& Zakharov, 1980) and, indeed, mitochondria have been

†Present address: Instituto de Química, Universidade de Sáo Paulo, Brazil.

Abbreviations: Hsp, heat-shock protein; ROS, reactive oxygen species; SOD, superoxide dismutase. suggested as a target for ethanol damage (Aguilera \& Benitez, 1985; Sá-Correia \& van Uden, 1986). As for other stress conditions, $S$. cerevisiae cells seem to be more ethanol tolerant when they reach the stationary phase (Werner-Washburne et al., 1993; Piper, 1995). Exponential-phase cells can also become tolerant to lethal ethanol concentrations if they undergo a previous sublethal heat or ethanol stress (Watson \& Cavicchioli, 1983; Costa et al., 1993). During both these stress adaptations, the expression of a subset of proteins is highly induced (Plesset $e t$ al., 1982; Werner-Washburne et al., 1993), including the stress proteins Hsp26, Hsp30 (Panaretou \& Piper, 1992), Hsp70, Hsp104 (Sanchez et al., 1992), catalase T (Belazzi et al., 1991; Wieser et al., 1991) and MnSOD (Costa et al., 1993). However, only Hsp104 and MnSOD were shown to be required for the acquisition of ethanol tolerance. Plasma membrane 
ATPase activity (Panaretou \& Piper, 1990; Rosa \& SáCorreia, 1996), as well as the accumulation of trehalose (Odumeru et al., 1993) and the increase in membrane concentrations of unsaturated fatty acids and ergosterol (Beaven et al., 1982; Del Castillo Agudo, 1992), were also correlated with ethanol tolerance (Piper, 1995).

We have previously reported that the mitochondrial superoxide dismutase (MnSOD) plays a key role in the acquisition of ethanol tolerance in exponential-phase yeast cells (Costa et al., 1993). In addition to MnSOD, the system of primary antioxidant defences (enzymic and non-enzymic) includes CuZnSOD, cytochrome-cperoxidase, catalases $\mathrm{A}$ and $\mathrm{T}$, metallothionein, thioredoxin, thioredoxin-peroxidase and glutathione (Moradas-Ferreira et al., 1996). It has been found that in exponential yeast cells growing mainly by fermentation, the synthesis of many antioxidant defences is repressed, and that derepression only occurs at the diauxic shift phase, before the onset of respiratory growth (WernerWashburne et al., 1993; Moradas-Ferreira et al., 1996). Therefore, the induction of antioxidant defences during this respiratory adaptation may contribute to the increased oxidative stress tolerance observed in these cells (Jamieson, 1992). Ethanol toxicity was correlated with the production of reactive oxygen species (ROS), since MnSOD and catalase $T$ are induced by ethanol stress, leading to a higher ethanol tolerance (Costa et al., 1993; Wieser et al., 1991). Cells with increased levels of MnSOD and catalase $\mathrm{T}$ are able to avoid the damaging effects of ROS, such as superoxide $\left(\cdot \mathrm{O}_{2}^{-}\right)$and hydroxyl $(\cdot \mathrm{OH})$ radicals, and hydrogen peroxide $\left(\mathrm{H}_{2} \mathrm{O}_{2}\right)$ (Halliwell \& Gutteridge, 1989).

With the aim of understanding the role of both CuZnSOD (encoded by SOD1) and MnSOD (encoded by $S O D 2$ ) in the tolerance of $S$. cerevisiae to ethanol stress, we analysed mRNA-SOD levels and SOD activities during growth from the exponential to the postdiauxic phase. In addition, ethanol tolerance of mutant cells deficient in either CuZnSOD (sod1 cells) or MnSOD ( $\operatorname{cod} 2$ cells) was studied. The role of ROS in the induction of SODs under ethanol stress conditions was addressed using respiration-deficient mutants.

\section{METHODS}

Yeast strains and growth conditions. The strains of Saccharomyces cerevisiae used in this study are listed in Table 1. Respiration-deficient mutants were prepared by prolonged exposure to ethidium bromide and selected as cells unable to form colonies on YPG plates ( $1 \%$ yeast extract, $2 \%$ bactopeptone, $3 \%, \mathrm{v} / \mathrm{v}$, glycerol). Cells were grown in YPD $(1 \%$ yeast extract, $2 \%$ bactopeptone, $2 \%$ glucose) to early exponential phase $\left(\mathrm{OD}_{600} 0 \cdot 6\right)$, diauxic shift phase $\left(\mathrm{OD}_{600}\right.$ $3 \cdot 0 \pm 0 \cdot 1$ for the $\mathrm{aBR} 10$ strain; $\mathrm{OD}_{600} 3 \cdot 9 \pm 0 \cdot 1$ for DL1, DL1sod2 and Dscd2-2C strains) or post-diauxic phase $\left(\mathrm{OD}_{600}\right.$ $5 \cdot 7 \pm 0 \cdot 1$ for the $\mathrm{aBR} 10$ and DL1sod 2 strains; $\mathrm{OD}_{600} 7 \cdot 0$ for the DL1 strain; $\mathrm{OD}_{600} 9.0$ for the Dscd2-2C strain) (Fig. 1), in an orbital shaker, at $26^{\circ} \mathrm{C}$, and 120 r.p.m., with a ratio of flask volume/medium volume of $5: 1$. Growth of aBR10p and DL1sod2p cells (respiration-deficient mutants) in the exponential phase was similar to that observed in the aBR10 and DL1sod2 cells (data not shown).
Table 1. Saccharomyces cerevisiae strains

\begin{tabular}{|c|c|c|}
\hline Strain & Genotype & Reference/source \\
\hline aBR10 & $\begin{array}{l}\text { MATa gal1 trp1 his4 ade } \\
\text { cyc1 }\end{array}$ & $\begin{array}{l}\text { Rymond et al. } \\
\text { (1983) }\end{array}$ \\
\hline aBR10p* & {$[\mathrm{aBR} 10] \mathrm{rho}^{-}$} & This work \\
\hline Dscd2-2C & MAT $\alpha$ ura 3 arg 4 sod 1 & $\begin{array}{l}\text { Bilinski et al. } \\
\text { (1985) }\end{array}$ \\
\hline DL1 & $\begin{array}{l}\text { MATa bis3-11,3-15 } \\
\text { ura3-251,3-372,3-328 }\end{array}$ & $\begin{array}{l}\text { van Loon et al. } \\
\text { (1986) }\end{array}$ \\
\hline DL1sod2 & {$[\mathrm{DL} 1] \operatorname{sod} 2$} & $\begin{array}{l}\text { van Loon et al. } \\
(1986)\end{array}$ \\
\hline DL1sod2 $\mathrm{p}^{*}$ & [DL1] sod $2 \mathrm{rho}^{-}$ & This work \\
\hline
\end{tabular}

* Respiration-deficient mutants.

Ethanol tolerance. Yeast cells were grown to the diauxic shift or post-diauxic phase. Aliquots of these cultures were treated with $14 \%(v / v)$ or $20 \%(v / v)$ ethanol for $30 \mathrm{~min}$. Cultures of the sod2p strain, growing in early exponential phase $\left(\mathrm{OD}_{600}\right.$ $0.6)$ at $26^{\circ} \mathrm{C}$, or pre-exposed to a sublethal ethanol stress $(8 \%$, $\mathrm{v} / \mathrm{v}$ ) for $30 \mathrm{~min}$, were subsequently treated with $14 \%$ ethanol for 30 or $60 \mathrm{~min}$.

Cell viability was determined by standard dilution plate counts on YPD medium containing $1.5 \%$ agar. Colonies were counted after growth at $26^{\circ} \mathrm{C}$ for $3 \mathrm{~d}$.

SOD (EC 1.15.1.1) activity. Yeast extracts were prepared in $0.05 \mathrm{M}$ potassium phosphate buffer $(\mathrm{pH} 7.8)$ containing $0.1 \mathrm{mM}$ EDTA, by vigorous shaking of the cell suspension, in the presence of glass beads, for $3 \mathrm{~min}$. Short pulses of $30 \mathrm{~s}$ were used, with $30 \mathrm{~s}$ intervals on ice. Proteins were assayed by the Lowry method, using bovine serum albumin as a standard. One hundred micrograms of total protein was used for the enzyme assay. Total SOD activity was determined spectrophotometrically at $550 \mathrm{~nm}$, in the presence of cytochrome $c$, using the xanthine-xanthine oxidase system (Flohé \& Otting, 1984). MnSOD activity was assayed in the presence of $2 \mathrm{mM}$ $\mathrm{KCN}$. SOD activity of extracts was determined by reference to a standard curve prepared with known amounts of bovine SOD (Sigma), and expressed as $\mathrm{U}$ ( $\mathrm{mg}$ protein) ${ }^{-1}$. One unit of SOD is the amount of enzyme which inhibits the rate of cytochrome $c$ reduction by $50 \%$.

Preparation and analysis of RNA. RNA was isolated as described by Brown (1994). Total RNA $(30 \mu \mathrm{g})$ was denatured with glyoxal and dimethyl sulfoxide, blotted onto Hybond $\mathrm{N}$ membranes and probed as described by Sambrook et al. (1989). The following gene probes were used: a $0.5 \mathrm{~kb} H$ HindII fragment of the SOD1 gene (Bermingham-McDonogh et al., 1988); a $2 \mathrm{~kb}$ BamHI fragment of the SOD2 gene (Marres et al., 1985); a $1.1 \mathrm{~kb}$ EcoRI fragment of the CTT1 gene, encoding catalase $\mathrm{T}$ (Spevak et al., 1983); and a $1 \mathrm{~kb}$ HindIII-EcoRI fragment of the ACT1 gene, encoding actin (Gallwitz \& Sures, 1980). Band intensities were evaluated using an Ultra Scan XL Enhancer laser densitometer.

Statistical analysis. Data are expressed as mean values \pm SD of at least three independent experiments. Values were compared by Student's $t$-test. The 0.05 probability level was chosen as the point of statistical significance throughout. 


\section{RESULTS}

Ethanol does not induce SOD activities in cells growing from the diauxic shift to the post-diauxic phase

As previously shown for exponentially growing cells, ethanol induces MnSOD activity, which could be correlated with the acquisition of ethanol tolerance (Costa et al., 1993). As the post-diauxic-phase yeast cells are resistant to high concentrations of ethanol (Piper, 1995), we analysed the build-up of this tolerance by determining the SOD activities and levels of mRNA$S O D 1$ and $\mathrm{mRNA}-S O D 2$ in $S$. cerevisiae aBR10 cells during the different growth phases (Fig. 1). CuZnSOD and MnSOD activities increased $100 \%$ and $200 \%$,

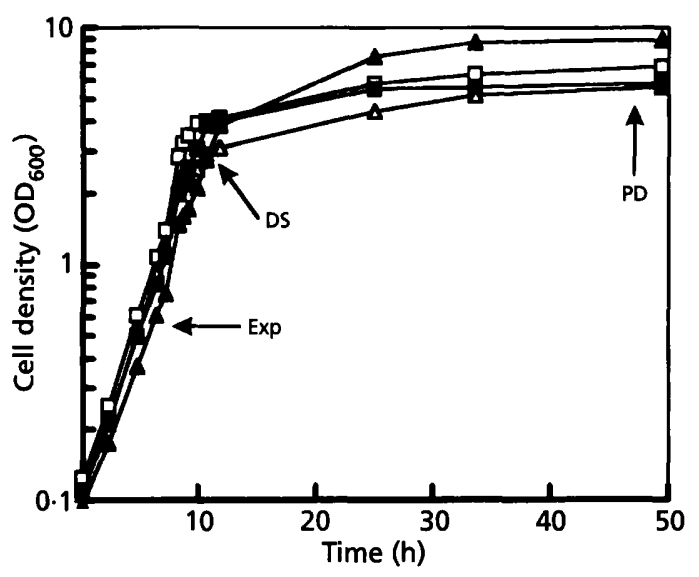

Fig. 1. Growth of S. cerevisiae aBR10 ( $\triangle$ ), DL1 $(\square)$, sod1 (A) and sod2 ( $\square$ ) cells in YPD medium. Arrows indicate the growth phases at which the experiments were performed: the exponential phase (Exp), the diauxic shift phase (DS) and the post-diauxic phase (PD). respectively, from the exponential phase to the diauxic shift, and $35 \%$ and $170 \%$, respectively, from the diauxic shift to the post-diauxic phase (Fig. 2a). Exposure of diauxic shift or post-diauxic phase cells to ethanol $(14 \%$ or $20 \%, \mathrm{v} / \mathrm{v}$ ) did not significantly affect either CuZnSOD or MnSOD activity (Fig. 2b). To assess whether the increased SOD activities were due to the synthesis de novo of the proteins, we analysed the respective mRNA levels. Our results (not shown) confirmed the data previously obtained by Galiazzo \& Labbe-Bois (1993): both mRNA-SOD1 and mRNA-SOD2 levels increased threefold during growth from the exponential to the diauxic shift phase. However, during growth to the post-diauxic phase, mRNA-SOD1 levels decreased $40 \%$, while mRNA-SOD2 levels remained identical (Fig. 3). When post-diauxic cells were stressed with ethanol, both mRNA levels were further reduced 30 $40 \%$. A similar depletion of mRNA-CTT1 and mRNAACT1 was observed (Fig. 3a). This effect on mRNA$S O D$ levels suggests that, besides a general decrease for mRNA levels as cells enter the post-diauxic phase, ethanol stimulates mRNA degradation or inhibits transcription. In contrast, ethanol did not affect mRNA$S O D$ levels of cells from the diauxic shift (Fig. 3) or exponential phase (Fig. 4). Notably, in exponentially growing cells, heat shock induced a 2 -fold increase for mRNA-SOD1 and a $2 \cdot 5$-fold increase for mRNA-SOD2 (Fig. 4).

\section{MnSOD deficiency renders post-diauxic phase yeast cells hypersensitive to ethanol}

The results in Fig. 2 suggested that ethanol tolerance at the post-diauxic phase is associated with a higher activity of CuZnSOD and MnSOD. Considering the role of SODs in ethanol tolerance, it was decided to assess the relevance of each enzyme during growth using sod1 and sod 2 null mutants.
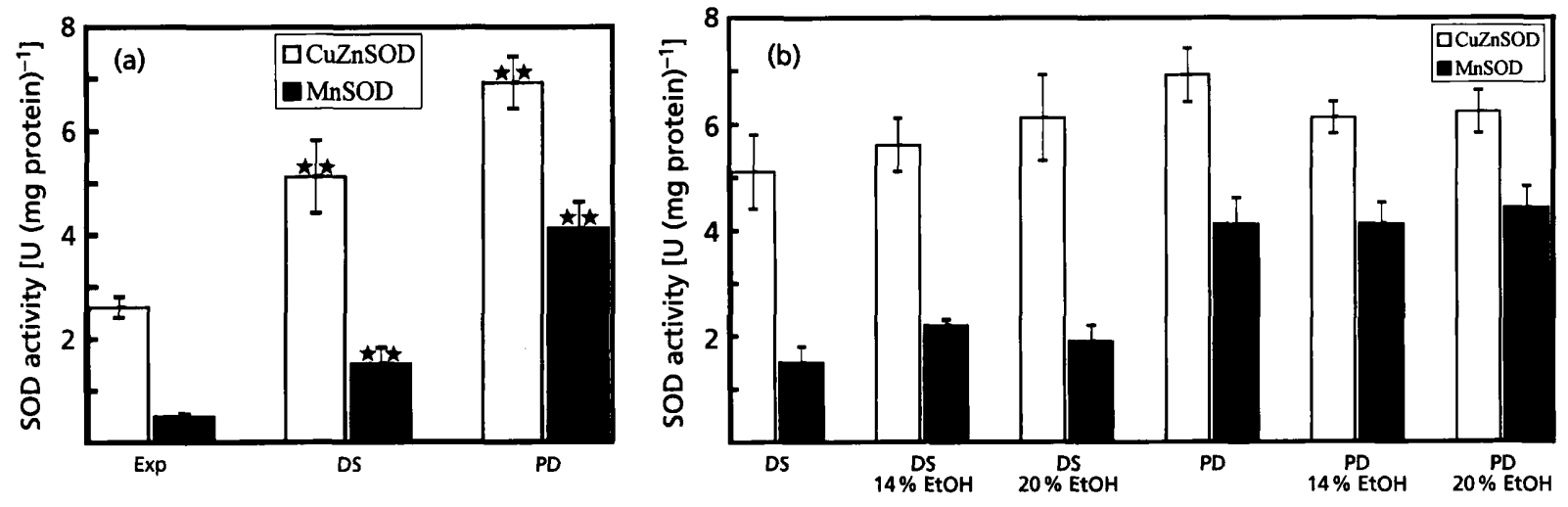

Fig. 2. Analysis of CUZnSOD and MnSOD activities in S. cerevisiae aBR10 cells. (a) Both CuZnSOD and MnSOD activities increase during growth from the exponential (Exp) to the diauxic shift (DS) and post-diauxic (PD) phases [results for exponential-phase cells are from Costa et al. (1993)]. Values are means \pm SD of five independent experiments. ${ }^{* \star P} P 0.05$ (DS compared to Exp, and PD to DS). (b) Exposure of diauxic shift (DS) and post-diauxic (PD) cells to $14 \%$ (v/v) or $20 \%$ $(v / v)$ ethanol for $30 \mathrm{~min}$ does not affect CuZnSOD or MnSOD activity. Values are means $\pm S D$ of five independent experiments. 
(a)

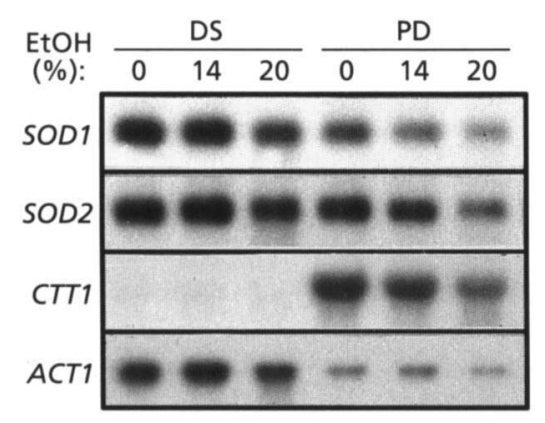

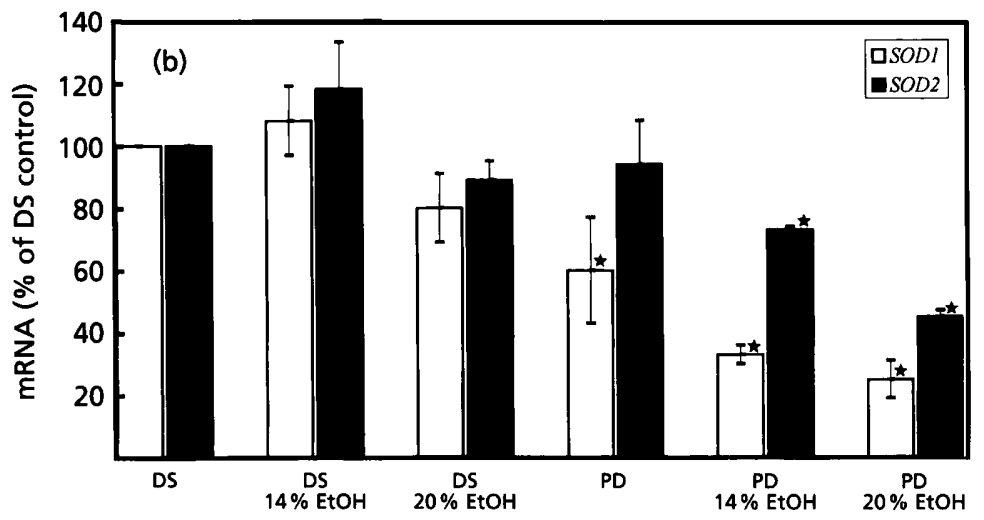

Fig. 3. (a) Northern blot analysis of mRNA-SOD1 (CUZnSOD gene), mRNA-SOD2 (MnSOD gene) and mRNA-CTT1 (catalase $T$ gene) in S. cerevisiae aBR10 cells. Diauxic-shift (DS) and post-diauxic-phase (PD) cells growing in YPD were exposed to $14 \%(\mathrm{v} / \mathrm{v})$ or $20 \%(\mathrm{v} / \mathrm{v})$ ethanol for $30 \mathrm{~min}$. A representative experiment is shown. (b) mRNA-SOD1 and mRNA-SOD2 hybridization signals were quantified using a Ultra Scan XL Enhancer laser densitometer. As mRNA-ACT1 levels decrease in the PD phase, equal RNA loading was confirmed by ethidium bromide staining after electrophoresis. mRNA-SOD1 decreases in cells growing from the diauxic shift (DS) to the post-diauxic (PD) phase, while mRNA-SOD2 levels remain constant. Both mRNA levels decrease in PD cells exposed to $14 \%(\mathrm{v} / \mathrm{v})$ or $20 \%(\mathrm{v} / \mathrm{v})$ ethanol for 30 min. Values are means $\pm S D$ of three independent experiments. ${ }^{*} P<0.01$ (treated cells compared to control cells, and PD to DS).

(a)

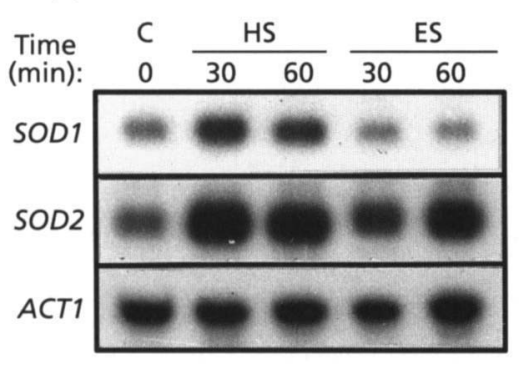

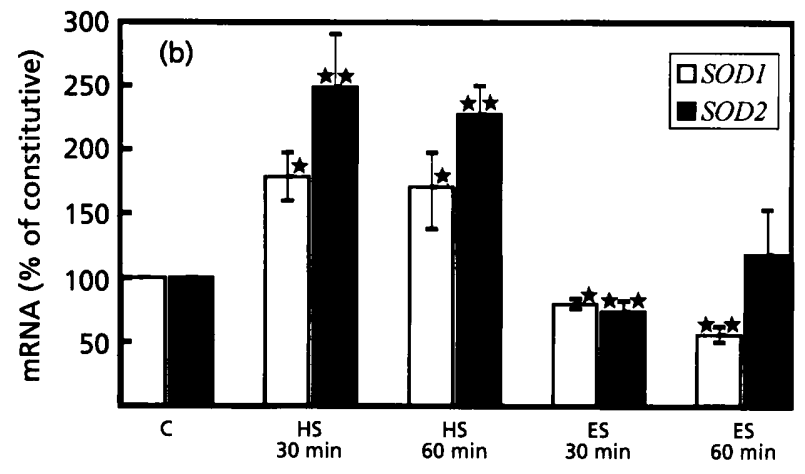

Fig. 4. (a) Northern blot analysis of mRNA-SOD1 (CuZnSOD gene) and MRNA-SOD2 (MnSOD gene) in exponential-phase cells of $S$. cerevisiae aBR10 growing in YPD. Cells were exposed to $8 \%$ ethanol (v/v) (ES) or heat stressed at $37^{\circ} \mathrm{C}(\mathrm{HS})$. $\mathrm{C}$, constitutive levels. A representative experiment is shown. (b) MRNA-SOD1 and MRNA-SOD2 band intensities were quantified and corrected for ACT1 (RNA loading control). mRNA-SOD1 and mRNA-SOD2 levels are not affected by $8 \%$ ethanol, but increase after a sublethal heat shock. Values are means \pm SD of three independent experiments. ${ }^{\star} P<0.01$; $\star \star P<0.05$.

In S. cerevisiae aBR 10 cells, $80-90 \%$ of cells from either the diauxic shift phase or the post-diauxic phase remained viable when exposed to $14 \%(\mathrm{v} / \mathrm{v})$ ethanol stress (Table 2). During the transition from the diauxic shift to the post-diauxic phase, cells became tolerant to higher ethanol concentrations, up to $20 \%$ (v/v): $55 \%$ of cells remained viable at the diauxic shift phase, while more than $80 \%$ of post-diauxic phase cells survived. The sod1 mutation did not impair the acquisition of ethanol tolerance during the transition to the diauxic shift and post-diauxic phase (Table 2). In contrast, the sod 2 mutation rendered yeast cells very sensitive to ethanol (Table 2). In this mutant, $100 \%$ of diauxic-shift cells and $90 \%$ of post-diauxic-phase cells became unviable after $30 \mathrm{~min}$ in the presence of $20 \%$ ethanol, whereas in aBR10 cells, as well as in DL1 cells (the isogenic, wild-type strain of the sod2 mutants; data not shown) only $45 \%$ cell death occurred in diauxic-shift cells and $20 \%$ in post-diauxic-phase cells. Despite the high sensitivity of sod 2 mutants to ethanol, their tolerance slightly increased in the post-diauxic phase, compared to the diauxic shift phase.

\section{Ethanol induces CuZnSOD activity of sod2 cells in the diauxic shift and post-diauxic phase}

As sod 2 cells are very sensitive to ethanol, but can still acquire a low degree of tolerance when they reach the post-diauxic phase, we analysed the contribution of $\mathrm{CuZnSOD}$ activity to the observed tolerance. CuZnSOD activity of sod 2 cells increased $40 \%$ during growth from the exponential to the diauxic shift phase (data not 
Table 2. Cells deficient in MnSOD are sensitive to ethanol

Cells of $S$. cerevisiae strains aBR10, Dscd2-2 $(\operatorname{sod} 1)$, and $\operatorname{sod} 2$, growing in YPD at the diauxic shift or in the post-diauxic phase, were treated with $14 \%(\mathrm{v} / \mathrm{v})$ or $20 \%(\mathrm{v} / \mathrm{v})$ ethanol for $30 \mathrm{~min}$. Appropriate dilutions were plated on YPD. Viable cells were assayed after growth at $26^{\circ} \mathrm{C}$ for $3 \mathrm{~d}$ and expressed relative to control cells (not treated with ethanol). Values are means \pm SD of five independent experiments.

\begin{tabular}{|c|c|c|c|c|}
\hline \multirow{3}{*}{$\begin{array}{l}\text { S. cerevisiae } \\
\text { strain }\end{array}$} & \multicolumn{4}{|c|}{ Viability (\%) } \\
\hline & \multicolumn{2}{|c|}{ Diauxic shift } & \multicolumn{2}{|c|}{ Post-diauxic } \\
\hline & $\begin{array}{c}14 \% \\
\mathrm{EtOH}\end{array}$ & $\begin{array}{l}20 \% \\
\mathrm{EtOH}\end{array}$ & $\begin{array}{c}14 \% \\
\text { EtOH }\end{array}$ & $\begin{array}{c}20 \% \\
\text { EtOH }\end{array}$ \\
\hline aBR10 & $90 \pm 3$ & $56 \pm 8$ & $79 \pm 7$ & $82 \pm 2$ \\
\hline sod1 & $83 \pm 10$ & $44 \pm 15$ & $87 \pm 11$ & $79 \pm 8$ \\
\hline $\operatorname{sod} 2$ & $72 \pm 3$ & $\overline{0}$ & $76 \pm 3$ & $9 \pm 3$ \\
\hline
\end{tabular}

Table 3. CuZnSOD activity increases in post-diauxic sod2 cells exposed to ethanol

Cells of $S$. cerevisiae sod 2 growing in YPD at the diauxic shift or in the post-diauxic phase were treated with $14 \%(\mathrm{v} / \mathrm{v})$ or $20 \%(\mathrm{v} / \mathrm{v})$ ethanol for $30 \mathrm{~min}$, and the activity of CuZnSOD was determined as described in Methods. Values are means \pm SD of five independent experiments. ${ }^{*} P<0.01$; $* * P<0.05$ (treated cells compared to control cells, and postdiauxic to diauxic shift).

\begin{tabular}{|c|c|c|}
\hline \multirow[t]{2}{*}{ Ethanol (\%) } & \multicolumn{2}{|c|}{$\begin{array}{l}\text { CuZnSOD activity } \\
{\left[\mathrm{U}(\mathrm{mg} \text { protein })^{-1}\right]}\end{array}$} \\
\hline & Diauxic shift & Post-diauxic \\
\hline 0 & $5 \cdot 5 \pm 0 \cdot 3$ & $8 \cdot 5 \pm 0.7^{* *}$ \\
\hline 14 & $5 \cdot 6 \pm 0.3$ & $12 \cdot 9 \pm 1 \cdot 4^{*}$ \\
\hline 20 & $6.5 \pm 0.2^{*}$ & $16 \cdot 1 \pm 1 \cdot 5^{* * *}$ \\
\hline
\end{tabular}

shown), and $55 \%$ from the diauxic shift to the postdiauxic phase (Table 3). Similar changes were observed in aBR 10 cells (Fig. 2a). Interestingly, CuZnSOD activity in the post-diauxic phase was higher in sod 2 cells $[8.5 \mathrm{U}$ $\left.(\mathrm{mg} \text { protein })^{-1}\right]$ than in the aBR10 strain $[6.9 \mathrm{U}(\mathrm{mg}$ protein $)^{-1}$ ], and further increased $50-90 \%$ when sod 2 cells were exposed to $14 \%$ or $20 \%$ ethanol (Table 3), in contrast to the lack of effect observed in aBR10 cells (Fig. 2b).

\section{Ethanol induction of MnSOD activity is low in respiration-deficient mutants}

The high sensitivity of sod 2 cells to ethanol supports the correlation between ethanol toxicity and production of ROS in the mitochondria. Therefore, we addressed the question of whether a respiratory deficiency would increase ethanol tolerance of sod 2 cells, since the generation of reactive species in the mitochondria is impaired. Indeed, the tolerance to $14 \%$ ethanol of respiration-deficient sod2 cells (S. cerevisiae sod2p) growing exponentially was significantly enhanced when cells were pre-exposed to $8 \%$ ethanol for $30 \mathrm{~min}: 15 \%$ of exponential-phase cells were able to form colonies after exposure to $14 \%$ ethanol for $60 \mathrm{~min}$, while $80 \%$ of ethanol-pretreated cells remained viable. This acquisition of ethanol tolerance by sod2p cells was similar to that observed in the wild-type strain, $S$. cerevisiae DL1 (data not shown).

To investigate if ROS are involved in the induction of $\mathrm{MnSOD}$, the activity was analysed in respirationdeficient mutants of the aBR10 strain ( $S$. cerevisiae aBR10p). The constitutive SOD activities of aBR10p mutants (Fig. 5a) were identical to those of wild-type cells (Fig. 2a); however, when cells were exposed to $8 \%$ ethanol, only a small increase of MnSOD activity was observed (Fig. 5a). A comparative analysis with heat shock showed no significant effect on the activity of either enzyme (Fig. 5a). The analysis of mRNA levels showed that ethanol treatment caused decreased mRNA-SOD1 levels in the aBR10p strain, similar to the effect observed in wild-type cells, but caused an increase in mRNA-SOD2 (90\% after $60 \mathrm{~min}$; Fig. 5b). Heat shock did not affect mRNA-SOD1 levels and increased the levels of mRNA-SOD2 $(45 \%$ and $95 \%$ after 30 and $60 \mathrm{~min}$, respectively); however the induction was lower than that determined in aBR 10 cells $(150 \%$ and $130 \%$, respectively).

\section{DISCUSSION}

When exponential-phase cells of $S$. cerevisiae growing on glucose are exposed to a sublethal thermal or ethanol stress, antioxidant defences, such as MnSOD and catalase $\mathrm{T}$, are induced and ethanol tolerance increases (Watson \& Cavicchioli, 1983; Wieser et al., 1991; Costa et al., 1993; Schuller et al., 1994). The yeast cells can also become more tolerant to ethanol and other stress agents when they shift from fermentative to respiratory growth (Piper, 1995). Indeed, when fermentation comes to an end, a number of genes downregulated by glucose are activated, including genes encoding antioxidant defences (Werner-Washburne et al., 1993; MoradasFerreira et al., 1996). As previously reported, the acquisition of ethanol tolerance is dependent on the activity of MnSOD (Costa et al., 1993). The present work was aimed at analysing the correlation between the activity of CuZnSOD and MnSOD and ethanol tolerance during different phases of growth.

When cells enter the diauxic shift phase, the activity of both SODs increased. This increase in activity was correlated with higher levels of mRNA, and thus with an increased translation of the apoproteins. However, measurements of the dismutase activity of cells in the post-diauxic phase revealed that the activity of $\mathrm{CuZn}$ SOD was only moderately induced while the activity of 

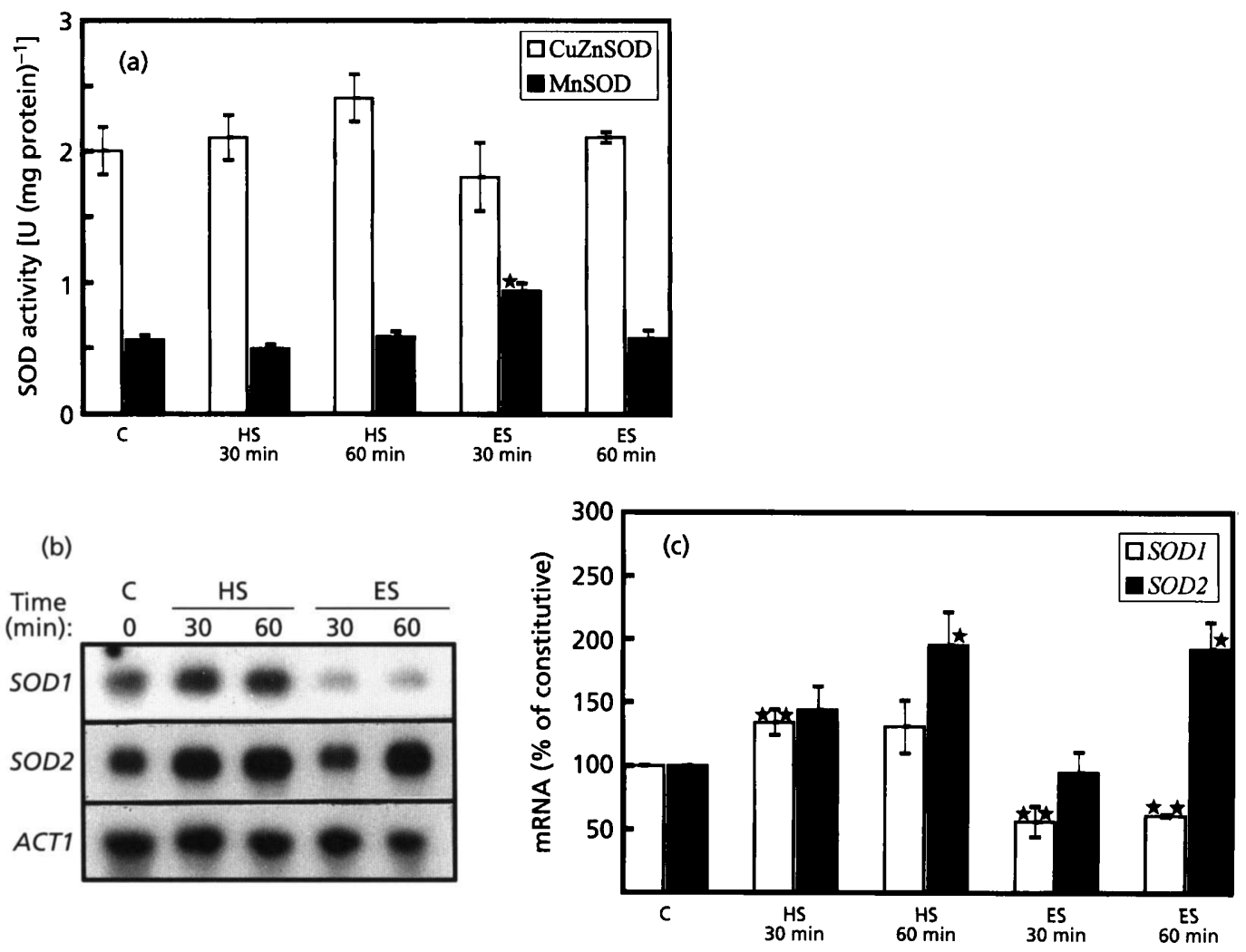

Fig. 5. Analysis of SOD in exponential $S$. cerevisiae aBR10p cells exposed to a sublethal heat shock (HS; $37{ }^{\circ} \mathrm{C}$ ) and $8 \%(v / v)$ ethanol stress (ES). C, constitutive levels. (a) CuZnSOD activity is not affected by either a heat shock or ethanol stress, while MnSOD activity is transiently induced by ethanol. Values are means $\pm S D$ of five independent experiments. ${ }^{*} P<0.01$. (b) Northern blot analysis of mRNA-SOD1 (CuZnSOD gene) and mRNA-SOD2 (MnSOD gene) levels (a representative experiment is shown). (c) mRNA-SOD1 and MRNA-SOD2 band intensities were quantified and corrected for ACT1 (RNA loading control). mRNA-SOD1 levels are not induced by heat shock and even decrease during ethanol treatment. mRNA-SOD2 levels increase upon heat shock and ethanol stress. Values are means $\pm S D$ of three independent experiments. ${ }^{*} P<0.01 ; * * P<0.05$.

MnSOD was much more significantly induced, and this occurred while mRNA-SOD1 levels decreased and mRNA-SOD2 remained constant, compared to diauxicshift cells (Figs 2 and 3). These results suggest that the induction of $\mathrm{CuZnSOD}$ and MnSOD during growth from exponential to diauxic shift phase is due to a de novo synthesis of the proteins. In contrast, their induction during growth into the post-diauxic phase involves post-transcriptional regulatory mechanisms or post-translational activation of the apoproteins. These post-transcriptional regulatory mechanisms have been shown to occur in yeast cells. The CuZnSOD apoprotein is post-translationally activated by copper during aeration of hypoxic cells both in yeast and mammalian cells (Galiazzo et al., 1991; Rossi et al., 1994). An increased translatability of mRNA-RAS2, -ENO1, -RPB4 and $-B C Y 1$, and post-translational modifications of $B c y 1 p$ have been observed as cells grow into the post-diauxic phase (Brevario et al., 1988; Jigami et al., 1986; WernerWashburne et al., 1991).

When post-diauxic phase cells were stressed with ethanol, the dismutase activity did not change; however, the levels of both mRNA-SODs decreased. A similar depletion of mRNA-CTT1 and mRNA-ACT1 indicates that ethanol either stimulates mRNA degradation in general or represses gene transcription.

The high SOD activities and ethanol tolerance observed in post-diauxic yeast cells suggest a possible correlation between these two phenotypes. The role of MnSOD in ethanol tolerance is supported by the high sensitivity of sod2 mutant cells to ethanol during growth. However, sod 2 cells are still more tolerant in the post-diauxic phase than in the diauxic shift phase, adding support to the idea that other factors might be involved that are induced at the post-diauxic phase, such as Hsp26, Hsp104 and catalase $\mathrm{T}$, together with changes in membrane lipids (Piper, 1995).

It is clear that ethanol tolerance is independent of CuZnSOD activity, as sod 1 mutant cells display a tolerance similar to that of wild-type cells during all growth phases. Furthermore, despite the higher CuZnSOD activity found in sod 2 mutants in the post-diauxic phase $\left[8.5\right.$ vs $\left.6.9 \mathrm{U}(\mathrm{mg} \text { protein })^{-1}\right]$, these cells were highly sensitive to ethanol (Tables 2 and 3 ). However, CuZnSOD may play a minor role in ethanol tolerance of 
cells deficient in MnSOD. In fact, CuZnSOD activity increased in post-diauxic sod 2 cells exposed to ethanol, and these cells have a higher ethanol tolerance than diauxic shift cells. This minor role of CuZnSOD in ethanol tolerance was also suggested in exponentialphase cells (Costa et al., 1993). These results, however, cannot rule out an important role of $\mathrm{CuZnSOD}$ in other stress tolerances associated with post-diauxic-phase cells (Werner-Washburne et al., 1993). The localization of MnSOD in the mitochondrial matrix, where most of the ROS are produced during respiration, seems to be important for ethanol tolerance. By trapping $\cdot \mathrm{O}_{2}^{-}$ produced in excess within mitochondria of yeast cells under ethanol stress conditions, MnSOD would prevent its diffusion to the cytosol, thereby protecting lipids, proteins and nucleic acids from oxidative damage (Halliwell \& Gutteridge, 1989). The $\mathrm{H}_{2} \mathrm{O}_{2}$ produced by dismutation of $\cdot \mathrm{O}_{2}^{-}$catalysed by $\mathrm{MnSOD}$ can be decomposed by catalase $T$. It has been shown that the CTT1 gene is derepressed in the post-diauxic phase, as well as upon heat or ethanol stress of exponential-phase cells (Wieser et al., 1991; Schuller et al., 1994). In fact the highest ethanol tolerance is achieved by the coordinated action of MnSOD and catalase T. The induction of CTT1 is higher in exponential-phase cells exposed to ethanol than in those exposed to heat shock, and sublethal ethanol pretreatment confers higher ethanol tolerance than a sublethal thermal stress (Costa et al., 1993). In addition, CTT1 is only derepressed in the postdiauxic phase, and these cells are more tolerant to ethanol than diauxic-shift cells (Piper, 1995).

If ethanol induces the generation of $\cdot \mathrm{O}_{2}^{-}$in mitochondria, it would be expected that a respirationdeficient strain would be more tolerant to ethanol. Indeed, in contrast to sod 2 cells, exponentially growing sod2p cells are able to acquire ethanol tolerance. Besides, the data also indicate that $\cdot \mathrm{O}_{2}^{-}$may regulate $S O D$ expression upon thermal or ethanol stress. In fact, the levels of mRNA-SOD1 and mRNA-SOD2 increased upon heat shock and mRNA-SOD2 increased upon ethanol stress; however the induction was lower than that observed in wild-type cells (Figs 4 and 5). The induction of MnSOD activity by ethanol was rather low in petite (respiration-deficient) cells and no longer occurred upon heat shock, compared with wild-type cells, giving further evidence of a post-translational regulation of $\mathrm{MnSOD}$, which may involve $\cdot \mathrm{O}_{2}^{-}$under these stress conditions.

\section{ACKNOWLEDGEMENTS}

This work was supported by a grant PRAXIS XXI 2/2.1/ BIO/20/94. We thank Drs E. Gralla and L. Grivel for providing the SOD1 and SOD2 plasmids, respectively, and Drs T. Bilinski and A. P. G. M. van Loon for providing the Dscd2-2C and DL1sod2 strains, respectively.

\section{REFERENCES}

Aguilera, A. \& Benitez, T. (1985). Role of mitochondria in ethanol tolerance of Saccharomyces cerevisiae. Arch Microbiol 142, 389-392.
Bandas, E. L. \& Zakharov, I. A. (1980). Induction of rho mutations in yeast Saccharomyces cerevisiae by ethanol. Mutat Res 71, 193-199.

Beaven, M. J., Charpentier, C. \& Rose, A. H. (1982). Production and tolerance of ethanol in relation to phospholipid fatty acyl composition in Saccharomyces cerevisiae NCYC 431. J Gen Microbiol 128, 1447-1455.

Belazzi, T., Wagner, A., Wieser, R., Schanz, M., Adam, G., Hartig, A. \& Ruis, H. (1991). Negative regulation of transcription of the Saccharomyces cerevisiae catalase T (CTT1) gene by cAMP is mediated by a positive control element. EMBO J 10, 585-592.

Bermingham-McDonogh, O., Gralla, E. B. \& Valentine, J. S. (1988). The copper, zinc-superoxide dismutase gene of Saccharomyces cerevisiae: cloning, sequencing and biological activity. Proc Natl Acad Sci USA 85, 4789-4793.

Bilinski, T., Krawiek, Z., Liczmanski, A. \& Litwinska, J. (1985). Is hydroxyl radical generated by the Fenton reaction in vivo? Biochem Biophys Res Commun 130, 533-539.

Brevario, D., Hinnebusch, A. G. \& Dhar R. (1988). Multiple regulatory mechanisms control the expression of the RAS1 and RAS2 genes of Saccharomyces cerevisiae. EMBO J 7, 1805-1813.

Brown, A. J. P. (1994). Measurement of mRNA stability. In Molecular Genetics of Yeast: a Practical Approach, pp. 147-159. Edited by J. R. Johnston. Oxford: Oxford University Press.

Casey, G. P. \& Ingledew, W. M. (1986). Ethanol tolerance in yeasts. Crit Rev Microbiol 13, 219-280.

Costa, V., Reis, E., Quintanilha, A. \& Moradas-Ferreira P. (1993). Acquisition of ethanol tolerance in Saccharomyces cerevisiae: the key role of the mitochondrial superoxide dismutase. Arch Biochem Biophys 300, 608-614.

Del Castillo Agudo, L. (1992). Lipid content of Saccharomyces cerevisiae strains with different degrees of ethanol tolerance. Appl Microbiol Biotechnol 37, 647-651.

Flohé, L. \& Otting, F. (1984). Superoxide dismutase assays. Methods Enzymol 105, 93-104.

Galiazzo, F. \& Labbe-Bois, R. (1993). Regulation of $\mathrm{Cu}, \mathrm{Zn}$ - and Mn-superoxide dismutase transcription in Saccharomyces cerevisiae. FEBS Lett 315, 197-200.

Galiazzo, F., Ciriolo, M. R., Carri, M. T., Civitareale, P., Marcocci, L., Marmocchi, F. \& Rotilio, G. (1991). Activation and induction by copper of $\mathrm{Cu} / \mathrm{Zn}$ superoxide dismutase in Saccharomyces cerevisiae: presence of an inactive proenzyme in anaerobic yeast. Eur $J$ Biochem 196, 545-549.

Gallwitz, D. \& Sures, I. (1980). Structure of a split yeast gene: complete nucleotide sequence of the actin gene in Saccharomyces cerevisiae. Proc Natl Acad Sci USA 77, 2546-2550.

Halliwell, B. \& Gutteridge, J. M. C. (1989). Free Radicals in Biology and Medicine. Oxford: Clarendon Press.

Jamieson, D. J. (1992). Sacharomyces cerevisiae has distinct adaptative responses to both hydrogen peroxide and menadione. J Bacteriol 174, 6678-6681.

Jigami, Y., Toshimitsu, N., Fujisawa, H., Uemura, H., Tanaka, H. \& Nakasato, S. (1986). Analysis of expression of yeast enolase 1 gene containing a longer pyrimidine-rich region located between the TATA box and transcription start site. J Biochem 99, 1111-1125.

van Loon, A. P. G. M., Pesold-Hurt, B. \& Schatz, G. (1986). A yeast mutant lacking mitochondrial manganese superoxide dismutase is hypersensitive to oxygen. Proc Natl Acad Sci USA 83, 3820-3824.

Marres, C. A. M., van Loon, A. P. G. M., Oudshoorn, P., van Steeg, H., Grivell, L. A. \& Slater, E. C. (1985). Nucleotide sequence 
analysis of the nuclear gene coding for manganese superoxide dismutase of yeast mitochondria, a gene previously assumed to code for the Rieske iron-sulphur protein. Eur J Biochem 147, 153-161.

Moradas-Ferreira, P., Costa, V., Piper, P. \& Mager, W. (1996). The molecular defences against reactive oxygen species in yeast. $\mathrm{Mol}$ Microbiol 19, 651-658.

Odumeru, J. A., Damore, T., Russell, I. \& Stewart, G. G. (1993). Alterations in fatty-acid composition and trehalose concentration of Saccharomyces brewing strains in response to heat and ethanol shock. J Ind Microbiol 11, 113-119.

Panaretou, B. \& Piper, P. (1990). Plasma-membrane ATPase action affects several stress tolerances of Saccharomyces cerevisiae and Schizosaccharomyces pombe as well as the extent and duration of the heat shock response. J Gen Microbiol 136, 1763-1770.

Panaretou, B. \& Piper, P. (1992). The plasma membrane of yeast acquires a novel heat-shock protein (hsp30) and displays a decline in proton-pumping ATPase levels in response to both heat shock and entry to post-diauxic phase. Eur J Biochem 206, 635-640.

Piper, P. W. (1995). The heat shock and ethanol stress responses of yeast exhibit extensive similarity and functional overlap. FEMS Microbiol Lett 134, 121-127.

Plesset, J., Palm, C. \& Mclaughlin, C. S. (1982). Induction of heat shock proteins and thermotolerance by ethanol in Saccharomyces cerevisiae. Biochem Biophys Res Commun 108, 1340-1345.

Rosa, M. F. \& SáCorreia, I. (1996). Intracellular acidification does not account for inhibition of Saccharomyces cerevisiae growth in the presence of ethanol. FEMS Microbiol Lett 135, 271-274.

Rossi, L., Ciriolo, M. R., Marchese, E., Demartino, A., Giorgi, M. \& Rotilio, G. (1994). Differential decrease of copper content and of copper-binding to superoxide-dismutase in liver, heart and brain of copper-deficient rats. Biochem Biophys Res Commun 203, 1028-1034.

Rymond, B. C., Zitomer, R. S., Schumperli, D. \& Rosenberg, M. (1983). The expression in yeast of the Escherichia coli GALK gene on CYC1-GALK fusion plasmids. Gene 25, 249-262.
Sa-Correia, I. \& van Uden, N. (1986). Ethanol-induced death of Saccharomyces cerevisiae at low and intermediate growth temperatures. Biotechnol Bioeng 27, 301-303.

Sambrook, J., Fritsch, E. F. \& Maniatis, T. (1989). Molecular Cloning: a Laboratory Manual, 2nd edn. Cold Spring Harbor, NY: Cold Spring Harbor Laboratory.

Sanchez, Y., Taulien, J., Borkovich, K. M. \& Lindquist, S. (1992). Hsp104 is required for tolerance to many forms of stress. EMBO J 11, 2357-2364.

Schuller, C., Brewster, J. L., Alexander, M. R., Gustin, M. C. \& Ruis, H. (1994). The HOG pathway controls osmotic regulation of transcription via the stress response element (STRE) of Saccharomyces cerevisiae CTT1 gene. EMBO J 13, 4382-4389.

Spevak, W., Fessel, F., Rytka, J., Traczyk, A., Skoneczny, M. \& Ruis H. (1983). Isolation of the catalase T structural gene of Saccharomyces cerevisiae by functional complementation. Mol Cell Biol 3, $1545-1551$.

van Uden, N. (1984). Effects of ethanol on the temperature relations of viability and growth in yeasts. Crit Rev Biotechnol 1, 263-272.

Watson, K. \& Cavicchioli, R. (1983). Acquisition of ethanol tolerance in yeast cells by heat shock. Biotechnol Lett 5, 683-688.

Werner-Washburne, M., Brown, D. \& Braun, E. (1991). Bcy1, the regulatory subunit of cAMP-dependent protein kinase in yeast, is differentially modified in response to the physiological status of the cells. J Biol Chem 266, 19704-19709.

Werner-Washburne, M., Braun, E., Johnston, G. C. \& Singer, R. A. (1993). Stationary phase in the yeast Saccharomyces cerevisiae. Microbiol Rev 57, 383-401.

Wieser, R., Adam, G., Wagner, A., Schuller, C., Marchler, G., Ruis, H., Krawiek, Z. \& Bilinski, T. (1991). Heat shock-factor-independent heat control of transcription of the CTT1 gene encoding the cytosolic catalase T of Saccharomyces cerevisiae. J Biol Chem 266, 12406-12411.

Received 21 October 1996; revised 18 December 1996; accepted 14 January 1997. 